\title{
Natural Disaster and Its Devastation
}

Dr. Meghamala.S.Tavaragi ${ }^{1}$, Mrs. Sushma. $C^{2}$, Dr. Srinivas Kosgi ${ }^{3}$, Mrs. Mallika. B. N², Mrs. Gayatri Hegde ${ }^{4}$, Mr. Susheel Kumar. V. Ronad ${ }^{5}$

\section{ABSTRACT}

'Disaster is a crisis situation that far exceeds the capabilities'. Disaster includes natural and man- made disasters. Natural disasters are brought about by change in natural phenomenon or what is known as acts of God. Manmade disasters are also known as anthropogenic disasters and they as a result of human intent, error or as a result of failed systems. Natural disasters include things such as floods, volcanic eruptions, earthquakes, floods, tornadoes, landslides and hurricanes. Manmade disasters are technological hazards, sociological hazards and transportation hazards etc. Earthquake being a type of natural disaster is being given specific importance in these journal due to recent devastating effects of earthquake in Nepal and neibouring countries like India. Along with incidence of Nepal earthquake, list of 10 most powerful earthquakes is mentioned to know the magnitude of devastation caused by earthquake. Like earthquake, be it any disaster, manmade or natural, almost everyone in the population is affected by it. It gives a brief account of psychiatric morbidities due to disasters in India. Those who suffer damage are called victims. The victims may die or live. Those who manage to live are called survivors. No particular event is guaranteed to result in post-traumatic psychopathology. It also mentions briefly of what disaster is and types of disasters are natural and manmade.

Keywords: Natural Disaster, Devastation

'Disaster' is defined as a crisis situation causing wide spread damage which far exceeds our ability to recover.

Disasters fall into two major categories. These include man- made and natural disasters. Natural disasters are brought about by change in natural phenomenon or what is known as acts of

${ }^{1}$ Senior Resident (Psychiatrist), Dept of Psychiatry, Dimhans, Dharwad, Karnataka.

${ }^{2}$ Clinical Psychologist, Dept of Psychology, Dimhans, Dharwad, Karnataka.

${ }^{3}$ Associate Professor, Dept of Psychiatry, Dimhans, Dharwad, Karnataka

${ }^{4}$ Assistant Professor, Dept of Psychology, Dimhans, Dharwad, Karnataka.

${ }^{5}$ Assistant Professor, Dept of Nursing, Dimhans, Dharwad, Karnataka

(C) 2015 I M Tavaragi, C Sushma, S Kosgi, B Mallika, G Hegde, S Ronad; licensee IJIP. This is an Open Access Research distributed under the terms of the Creative Commons Attribution License (http://creativecommons.org/licenses/by/2.0), which permits unrestricted use, distribution, and reproduction in any Medium, provided the original work is properly cited. 
God. The extent of loss experienced is dependent on the vulnerability of the population. As such, this means that this can only occur in areas that are susceptible to vulnerability. On the other hand, manmade disasters are influenced by humans and they are often as a result of negligence and human error among other factors.

- Natural disasters: Natural disasters include things such as floods, volcanic eruptions, earthquakes, floods, tornadoes, landslides and hurricanes.

- Manmade disasters: These can be divided into different categories and they include technological hazards, sociological hazards and transportation hazards among others.

Whether the disaster is natural or manmade, the manner in which action is taken goes a long way to determine how people fair from the experience. In both instances, casualties should be treated immediately and the best way to meet this end is placing the necessary measures in place that counteract this. The costs associated with handling of the manmade and natural disasters run to billions of shillings every year and this negatively affects the economy.

\section{DEFINING DISASTER AND ITS TYPES:}

Disasters are not totally discrete events. Their possibility of occurrence, time, place and severity of the strike can be reasonably and in some cases accurately predicted by technological and scientific advances. It has been established there is a definite pattern in their occurrences and hence we can to some extent reduce the impact of damage though we cannot reduce the extent of damage itself (Juan, George, Mario, Norman, \& Ahmed, 2002).

- 'Disaster is a crisis situation that far exceeds the capabilities' ("Quarentelly, 1985”). 'Disaster' is defined as a crisis situation causing wide spread damage which far exceeds our ability to recover. Thus, by definition, there cannot be a perfect ideal system that prevents damage, because then it would not be a disaster. It has to suffocate our ability to recover. Only then it can be called as 'disaster'.

- 'Disasters, whether natural or manmade, affect lives and property, devastating communities through a chain of catastrophic sequences affecting social and economic developments.' (Cohen, 2002).

\section{TYPES OF DISASTER: NATURAL AND MANMADE DISASTERS}

Disasters fall into two major categories. These include man- made and natural disasters. Natural disasters are brought about by change in natural phenomenon or what is known as acts of God. The extent of loss experienced is dependent on the vulnerability of the population. As such, this means that this can only occur in areas that are susceptible to vulnerability. On the other hand, man made disasters are influenced by humans and they are often as a result of negligence and human error among other factors. 
Despite the difference between these two, it is ideal to note that they can cause irrevocable damage if the right measures are not put in place to avoid the same. This is where the need for disaster preparedness comes in. It goes a long way to cushion people from the after effects of such happenings. There are several sources that provide useful resources that make it possible to meet this end.

\section{- Man Made Disasters:}

Man made disasters are also known as anthropogenic disasters and they as a result of human intent, error or as a result of failed systems. A good example is to look at man made disasters such as transportation. These are divided into different categories which include aviation, rail, road and space among others. Often these are as a result of neglect or ignorance and over the years, they have claimed several lives.

Another type of disaster that falls in this category is nuclear bomb. When this occurs, it is often as a result of intent and the end results are even more catastrophic with a large percentage of those involved losing their lives or alternatively ending up with major defects or long term injuries. Other types of man made disasters which are just as catastrophic include chemical spill, oil spill, arson and terrorism. There are also some technological hazards which include power outages structural collapse, industrial hazards and fire. In cases of the last example, thousands of kilometers of land can be destroyed and anything else that is in the wake of the fires path.

Over the years, fires have come to be known as rampant man made disasters and they are also divided into different categories such as bush fires, mine, wild and firestorms. One of the most famous man made disasters in the form of fire was the Pennsylvania fire which was recorded in 1962. It left major distraction in its wake by destroying a town and to date, such fires continue to burn. Whenever people suffer injuries due to any of the mentioned man made factors, the condition is further aggravated if they don't get any immediate health care.

The extent of damage caused by man made disasters varies greatly and while this is the case, it is important to state that others have notably high costs when compared to others. The death toll caused by man made disasters will also vary in accordance to geographical location and in this regard, the poorer countries are hardest hit when compared to the richer ones. This is attributed to the fact that the richer countries have what it take to respond with speed to calls of distress, and can implement the proper safety measures needed from a distance to handle things safely and rapidly. Modern technology plays a very important role too. On the other hand, the poorer countries have no resources or assets to respond with. 


\section{Man-Made and Technological Types of Disasters}

- Hazardous materials

- Power service disruption \& blackout

- $\quad$ Nuclear power plant and nuclear blast

- $\quad$ Radiological emergencies
- Chemical threat and biological weapons

- $\quad$ Cyber attacks

- Explosion

- Civil unrest

(J:Idisaster management $\backslash$ Types of Disaster - Natural and Man-Made - Restore Your Economy.html)

\section{- Natural Disasters}

Disasters only occur when hazards come face to face with vulnerability. As such, when natural occurrences that bring about damage and there are no casualties, then it is not referred to as natural disasters. There are people who are of the school of thought that there is a difference between hazards and disaster and while this is the case, the after effects and casualties are almost always the same.

Some of the popular incidences include fires, tsunami, earthquakes, tornadoes and the floods. For instance, earthquakes are known to occur in areas that are earthquake prone. This is defined as the shaking of earth crust and it is brought about by shifting of the tectonic plates, Floods are also known to cause some of the worst natural disasters and this is especially true when they are accompanied by hurricanes. Hundreds of thousands of lives have been lost due to this and consequently, it is ranked among the most dreaded occurrences. These often occur in areas that are flood prone and for this reason it is always advised to avoid living in such areas. Other types of natural disasters that are just as disastrous include blizzards, droughts, fires, health disasters and space disasters among others (J:Idisaster management $\backslash$ Famous World Disasters by Both Humans and Nature.html) (2011-2015 Disasterium.com).

\section{Types of Natural Disasters}

- $\quad$ Agricultural diseases \& pests

- Damaging Winds

- $\quad$ Drought and water shortage

- Earthquakes

- Emergency diseases (pandemic influenza)

- Extreme heat

- $\quad$ Floods and flash floods

- $\underline{\text { Hail }}$
- $\quad$ Hurricanes and tropical storms

- Landslides \& debris flow

- Thunderstorms and lighting

- Tornadoes

- Tsunamis

- Wildfire

- Winter and ice storms

- $\underline{\text { Sinkholes }}$ 


\section{Brief view of disasters in India (INDIA):}

It has been acknowledged that India has been traditionally vulnerable to natural disasters on account of its unique geo-climatic conditions. Both natural and manmade disasters occur quite regularly in India, like many in the developing world (Mohandas, 2009, Rao, 2004, \& Khandelwal, 2006). About $60 \%$ of the Indian landmass is prone to earthquakes of various intensities; over 40 million hectares are prone to floods; about $8 \%$ of the total area is prone to cyclones and 68\% of the areas are susceptible to drought (Mohandas, 2009). Recent major natural disasters were Marathwada earth quake (1993), Andhra Pradesh cyclone (1996), Jabalpur earthquake (1997), super cyclone in Orissa (1999), Gujarat earthquake (2001) and tsunami in Tamil Nadu (2004). There have been major industrial accidents like Bhopal Gas tragedy (1984); the effects of which are still being felt. Manmade disasters are common too, like terrorism, communal riots and violence. Recently, the bomb blasts in many Indian cities and terror attack in Mumbai have been extremely traumatic.

\section{NATURAL DISASTER - AN EARTHQUAKE}

Earthquakes are known to occur in areas that are earthquake prone. It is defined as the shaking of earth crust and it is brought about by shifting of the tectonic plates. While this is a sudden and unanticipated shake, the magnitude varies and this determines the after effects and extent of percentage of the population suffering from it. Additionally, earthquakes are known to affects humans and animals alike. While the earthquake itself is not responsible for this, secondary effects which occur after the quake do. In most cases, this leads to collapse of buildings, triggering of fires and volcanoes among other manmade disasters. Some of the quakes that went down history books as worst natural disasters include the Indian Ocean quake which is the third strongest worldwide.

It had a magnitude of 9.1-9.3. It is known to have triggered one of the most major tsunamis which claimed the lives of more than 229,000. The recent one has to be the 2011 Tohuku quake and this one recorded a magnitude of 9.0. The death toll in this case is recorded to be more than 13,000 and to date more than 12,000 people are still recorded as missing. Other quakes worth noting include the java earthquake in 2006, the Chile quake in 2010. The last one was accompanied by tsunami that claimed more than 550 lives.

\section{THE 10 MOST POWERFUL RECORDED EARTH QUAKES}

\section{- 22 May 1960 - Chile}

\section{Magnitude 9.5}

The world's most powerful earthquake left 4,485 people dead and injured and 2 million homeless after it struck southern Chile in 1960. The port of Puerto Saavedra was destroyed in the ensuing tsunami, which caused \$550m worth of damage in Chile and killed a further 170 people as five- 
metre waves hit the coasts of Japan and the Philippines. A day later Volcán Puyehue in Chile's lake district spewed ash 6,000m into the air in an eruption that lasted for several weeks.

\section{March 1964 - Prince William Sound, Alaska}

\section{Magnitude 9.2}

The Gulf of Alaska was devastated by the Prince William Sound earthquake that caused landslides in Anchorage and raised parts of outlying islands by as much as 11 meters. The resulting tsunami reached heights of 67 meters as it swept into the shallow Valdez inlet and was responsible for most of the 128 deaths and $\$ 311 \mathrm{~m}$ worth of damage. The massive water displacement was felt as far away as the Louisiana Gulf coast and registered on tidal gauges in Puerto Rico.

- 26 December 2004 - Off the west coast of northern Sumatra

\section{Magnitude 9.1}

The deadliest tsunami in history was felt in 14 countries across Asia and east Africa, triggered by a "mega thrust" as the Indian tectonic plate was forced beneath the Burmese plate. Indonesia was the worst affected with an estimated 170,000 of the nearly 230,000 dead. With many of the victims' bodies missing, the eventual death toll took a month to establish. Some the world's poorest communities lost more than $60 \%$ of their fishing and industrial infrastructure.

\section{November 1952 - Kamchatka}

\section{Magnitude 9}

The volcanic Russian peninsula was near the epicenter of the quake, but it was the Hawaiian islands that took the brunt of the tsunami that caused a million dollars' worth of damage as waves scoured the coasts, ripping boats from their moorings and, in Honolulu harbor, lifting a cement barge before throwing it down on to a freighter. No deaths were recorded, unless you count the six cows lost by one unfortunate Oahu farmer, who was left cursing an event that had occurred more than 3,000 miles away.

\section{- 13 August 1868 - Arica, Peru (now part of Chile)}

\section{Magnitude 9}

Hawaii also felt the force of the tsunami created by this pacific basin earthquake, but here the destruction was just as heavy in South America with the city of Arequipa destroyed and 25,000 killed. The quake was felt as far away as La Paz in Bolivia. Four hours after the first shocks, 
waves as high as 16 meters inundated the coast and carried one US gunboat two miles inland to rest precariously on the edge of a $60 \mathrm{~m}$ cliff.

\section{January 1700 - North Pacific coast of America}

\section{Magnitude 9 (estimated)}

The only North American account of one of the continent's largest earthquakes comes from the oral history of Native Americans near Vancouver island which describes how the large community of Pachena bay was wiped out by a huge wave. Across the pacific, the quake was accurately recorded by Japanese observers of the large tsunami that struck Japan on 27 January 1700. The power of that inundation has been used by historians and seismologists to pinpoint the magnitude of the Vancouver quake.

- 27 February 2010 - off Bio-Bio, Chile

\section{Magnitude 8.8}

The region around Concepción has been recorded as a centre for seismic shocks since the 16th century, but few have been as devastating as the early morning quake that generated a Pacificwide tsunami and cost the lives of 521 people. With a further 12,000 injured and more than 800,000 left homeless, Chile was left reeling at the scale of a disaster that would cost the nation \$30bn by the end of 2010 .

\section{January 1906 - coast of Ecuador}

\section{Magnitude 8.8}

Emanating from the ocean off Ecuador and Colombia, the quake generated a tsunami that killed between 500 and 1,500 people along a coastline from Central America to San Francisco. To the west in Hawaii, rivers suddenly drained about 12 hours after the first shocks, then were submerged as a series of successively larger waves flooded the coast.

\section{November 1755 - Lisbon}

\section{Magnitude 8.7}

The near-total destruction of Lisbon and the deaths of a quarter of the city's population were caused by an earthquake, followed by a tsunami and fire, that was felt in north Africa, France and northern Italy. In the age of enlightenment, the cultural impact of the quake spread even further afield as the horrors of Lisbon provided inspiration for sensationalist artworks and 
philosophical tracts. Voltaire penned a poem on the catastrophe and scientists found a wealth of written first-hand accounts to advance their understanding of the physical world.

\section{August 1950 - Assam-Tibet}

\section{Magnitude 8.6}

Seventy villages simply disappeared in the string of disasters generated by an earthquake with an epicentre in Tibetan Rima but which wrought most destruction in India's Assam state. Across the region, landslides claimed the lives of 1,526 people and rendered parts of the landscape unrecognizable from the air. The quake was followed by severe flooding, and eight days after the first tremors a natural dam on the Subansiri River burst, releasing a seven-meter wall of water against nearby villages. Near the epicenter of the quake, witnesses mentioned "explosive sounds" that seemed to come from high in the air, while seismologists as far away as England and Norway noted "oscillations" in lakes. (Fairclough, 2011).

\section{RECENT EARTHQUAKE THAT DEVASTATED NEPAL}

The April 2015 Nepal earthquake (also known as the Gorkha earthquake (Nepal Seismological Centre. 2015, \& Chidanand, 2015), killed more than 8,800 people and injured more than 23,000. It occurred at 11:56 NST on 25 April, with a magnitude of $7.8 \mathrm{M}_{\mathrm{w}}$ (United States Geological Survey. 2015 or $8.1 \mathrm{M}_{\mathrm{s}}$ (China Earthquake Networks Center. 2015) and a maximum Mercalli Intensity of IX (Violent). Its epicenter was east of the district of Lamjung, and its hypocenter was at a depth of approximately $15 \mathrm{~km}$ (9.3 mi) (United States Geological Survey. 2015), It was the worst natural disaster to strike Nepal since the 1934 Nepal-Bihar earthquake (What 1934 Told Nepal to Expect About the Next Big Quake". ("Timeline: Nepal 2015 to 1934, the worst quake disasters in the last 80 years". 2015) ( "Nepal earthquake: Eerie reminder of 1934 tragedy"). The earthquake triggered an avalanche on Mount Everest, killing at least 19 (nytimes.com, 2015), making it the deadliest day on the mountain in history (Fox News, The Associated Press. 2015). It triggered another huge avalanche in the Langtang valley, where 250 people were reported missing (Shrestha, 2015, \& "Mail Online". 2015).

Hundreds of thousands of people were made homeless with entire villages flattened (Shrestha, 2015, McCarthy, 2015, \& Kaini, 2015), across many districts of the country. Centuries-old buildings were destroyed at UNESCO World Heritage sites in the Kathmandu Valley, including some at the Kathmandu Durbar Square, the Patan Durbar Squar, the Bhaktapur Durbar Square, the Changu Narayan Temple and the Swayambhunath Stupa. Geophysicists and other experts had warned for decades that Nepal was vulnerable to a deadly earthquake, particularly because of its geology, urbanization, and architecture (Washington Post. 2015, \& Colin, 2015).

Continued aftershocks occurred throughout Nepal within 15-20 minute intervals, with one shock reaching a magnitude of 6.7 on 26 April at 12:54:08 NST (usgs.gov.). The country also had a continued risk of landslides (Free Press Journal). A major aftershock occurred on 12 May 2015 
at 12:51 NST with a moment magnitude $\left(\mathrm{M}_{\mathrm{w}}\right)$ of 7.3 (The Natural Disasters). The epicenter was near the Chinese border between the capital of Kathmandu and Mt. Everest (BBC News. 2015). More than 200 people were killed and more than 2,500 were injured by this aftershock (Manesh, 2015).

Tremors were felt in the neighboring Indian states of Bihar, Uttar Pradesh, Assam, West Bengal, Sikkim, Jharkhand, Uttarakhand, Gujarat ("Andhra Pradesh earthquake update: Aftershocks of Nepal Earthquake felt in Visakhapatnam, Godavari and Srikakulam districts". 2015) in the Indian capital region around New Delhi ("Tremors felt in Delhi, Metro services briefly disrupted") and as far south as Karnataka ("In pics: 5,500 killed, more than 1/4th of Nepal's population affected after horrific earthquake"). Many buildings were brought down in Bihar. Minor cracks in the walls of houses were reported in Odisha. Minor quakes were registered as far as Kochi in the southern state of Kerala. The intensity in Patna was V (Moderate) (news.biharprabha.com. 2015). The intensity was IV (Light) in Dhaka, Bangladesh (United States Geological Survey. 2015). The earthquake was also experienced across southwestern China, ranging from the Tibet Autonomous Region to Chengdu, which is $1,900 \mathrm{~km}(1,200 \mathrm{mi})$ away from the epicenter (China News. 2015). Tremors were felt in Pakistan (Hjelmgaard, 2015) and Bhutan (United States Geological Survey. 2015).

A major aftershock of magnitude $6.7 \mathrm{M}_{\mathrm{w}}$ occurred on 26 April 2015 in the same region at 12:55 NST (07:09 UTC), with an epicenter located about $17 \mathrm{~km}$ (11 mi) south of Kodari, Nepal (Hjelmgaard, 2015 \& NDTV. 2015). The aftershock caused fresh avalanches on Mount Everest and was felt in many places in northern India including Kolkata, Siliguri, Jalpaiguri and Assam (The Indian Express. 2015). The aftershock caused a landslide on the Koshi Highway which blocked the section of the road between Bhedetar and Mulghat (kantipur.com. 2015).

A second major earthquake occurred on 12 May 2015 at 12:51 NST with a moment magnitude $\left(\mathrm{M}_{\mathrm{w}}\right)$ of $7.3 \mathrm{M}_{\mathrm{w}} 18 \mathrm{~km}$ (11 mi) southeast of Kodari. The epicenter was near the Chinese border between the capital of Kathmandu and Mt. Everest. It struck at the depth of $18.5 \mathrm{~km}$ (11.5 miles). This earthquake occurred along the same fault as the original magnitude 7.8 earthquake of 25 April but further to the east (United States Geological Survey. 2015). As such, it is considered to be an aftershock of the 25 April quake (United States Geological Survey. 2015) .Tremors were also felt in northern parts of India including Bihar, Uttar Pradesh, West Bengal and other NorthIndian States (news.biharprabha.com. 2015, BBC News.2015,United States Geological Survey. 2015). At least 117 died in Nepal as a result of the aftershock and about 2,500 were injured. Seventeen others died in India and one in China (Manesh, 2015, Manesh, Jethro, \& Laura, 2015). 


\begin{tabular}{|c|c|c|c|}
\hline COUNTRY & DEATHS & INJURIES & REFERNCES \\
\hline NEPAL & 8,675 & 21,950 & $\begin{array}{l}\text { (Nepal Disaster Risk Reduction } \\
\text { Portal. drrportal.gov.np. \& } \\
\text { National Emergency Operation } \\
\text { Centre (Nepal Govt.) on Twitter } \\
\text { (in Nepali).2015). }\end{array}$ \\
\hline INDIA & 130 & 560 & (Zee News. 2015). \\
\hline CHINA & 27 & 290 & (Xinhua.2015). \\
\hline BANGLADESH & 4 & 200 & (Bdnews24.com. 2015). \\
\hline TOTAL & $>8,836$ & $>23,000$ & \\
\hline
\end{tabular}

NEPAL: The earthquake killed more than 8,600 in Nepal (Nepal Disaster Risk Reduction Portal. drrportal.gov.np. 2015, \& Jason, \& Ishwar, 2015) and injured more than twice as many. The rural death toll may have been lower than it would have been as the villagers were outdoors, working when the quake hit (U.S. News and World Reports, 2015). As of 15 May, 6,271 people, including 1,700 from the 12 May aftershock, were still receiving treatment for their injuries (Manesh, Jethro, \& Laura, 2015). More than 450,000 people were displaced (National Emergency Operation Centre (Nepal Govt.) on Twitter (in Nepali). 2015). The Himalayan Times reported that as many as 20,000 foreign nationals may have been visiting Nepal at the time of the earthquake, although reports of foreign deaths were relatively low (The Himalayan Times via RT. 2015).

INDIA: A total of 78 deaths were reported in India - 58 in Bihar, 16 in Uttar Pradesh, 3 in West Bengal and 1 in Rajasthan (Zee News. 2015)

CHINA: 25 dead and 4 missing, all from the Tibet Autonomous Region (Xinhua. 2015)

BANGLADESH: 4 dead (Bdnews24.com. 2015) Avalanches on Mount Everest: This earthquake caused many avalanches on Mount Everest. At least 19 (Washington Post. 2015) died, including Google executive Dan Fredinburg (Los Angeles Times, 2015), with at least 120 (Washington Post. 2015) others injured or missing. Nepal, with a total Gross Domestic Product 
of USD\$19.921 billion (according to a 2012 estimate) (PrimePair. 2015), is one of Asia's poorest countries, and has little ability to fund a major reconstruction effort on its own (Bloomberg Business. 2015). Even before the quake, the Asian Development Bank estimated that it would need to spend about four times more than it currently does annually on infrastructure through to 2020 to attract investment (Bloomberg Business. 2015). The U.S. Geological Survey initially estimated economic losses from the temblor at 9 percent to 50 percent of gross domestic product, with a best guess of 35 percent. "It's too hard for now to tell the extent of the damage and the effect on Nepal's GDP", according to Hun Kim, an Asian Development Bank (ADB) official. The ADB said on the 28th that it would provide a USD\$3 million grant to Nepal for immediate relief efforts and up to USD\$200 million for the first phase of rehabilitation (Bloomberg Business. 2015).

Rajiv Biswas, an economist at a Colorado-based consultancy, said that rebuilding the economy will need international effort over the next few years as it could "easily exceed" USD\$5 billion, or about 20 percent of Nepal's gross domestic product ( Bloomberg Business. 2015, \& The New Indian Express. 2015).

\section{SURVIVORS AND VICTIMS}

Almost everyone in the population is affected by a disaster. No one is untouched by it. Those who suffer damage are called victims. The victims may die or live. Those who manage to live are called survivors.

SURVIVORS can be classified as,

1. Primary survivor - One who is exposed to the disaster first-hand and then survives. They are called 'survivor victims'.

2. Secondary survivor - One who grieves the loss of primary victims. Example, a mother who lost her child, or a man who lost his friend.

3. Third level survivor - The rescue and relief personnel. These people are also affected due to the disaster as they are at the site of disaster and undergo almost the same mental trauma as the other victims.

4. Fourth level survivor - Reporters, Government personnel, traders, etc.

5. Fifth level survivor - People who read about or see the event in media reports.

Some survivors experience an 'illusion of centrality', i.e. the feeling that only they have been adversely affected by the incident. (Juan, George, Mario, Norman, \& Ahmed, 2002). 
VICTIMS: Because of the ripple effect of major incidents, many individuals may legitimately be classified as victims even though they were not at the epicentre of the disaster (Taylor, \& Frazer, 1982).

A classification of victims

- Primary victims: those at the epicentre of the disaster

- Secondary victims: e.g. family and friends of primary victims

- Third-level victims: e.g. emergency and rescue personnel

- Fourth-level victims: e.g. members of the community who offer help

- Fifth-level victims: e.g. those disturbed through indirect involvement

- Sixth-level victims: e.g. those who, but for chance, might have been directly involved

\section{PSYCHIATRIC MORBIDITIES DUE TO NATURAL DISASTERS IN INDIA:}

A study conducted a month after the Latur earthquake found psychiatric morbidity in 59\%; posttraumatic stress disorder (PTSD) in 23\% and major depression in $21 \%$ being the common diagnoses (Sharan, Chaudhary, Kavathekar, \& Saxena, 1996). Another study following Latur earthquake in Marathwada revealed that survivors had PTSD (74\%), major depression (89\%), generalized anxiety disorder (GAD) (42\%) and panic disorder (28\%)(Kar, 2000). An Indian Council of Medical Research (ICMR) study in Latur found that $21.5 \%$ of adult males in the affected group received a psychiatric diagnosis compared to $13.1 \%$ in the controls; corresponding figures for adult females were $14.9 \%$ and 5.1\% respectively (Desai, Gupta, \& Srivastava,2004).

The psychiatric sequelae of the Orissa super-cyclone in 1999 suggested that $80.4 \%$ of the subjects had probable psychiatric disorder. PTSD was found in 44.3\%; anxiety disorder in 57.5\% and depression in 52.7\%. A considerable proportion (63.4\%) of victims with psychiatric disorder had comorbidity. Children and adolescents, elderly persons, lower socioeconomic status (SES), lower educational levels, unemployment, physical injury, degree of exposure, need for evacuation, death in the family, fear of imminent death during the event, hopelessness, increased stress before disaster and past psychiatric history were associated with adverse psychological sequelae. Increase in sociality was observed (Kar, Jagadisha, Sharma, Murali,\& Mehrotra, 2004).

Around one year after the super-cyclone in Orissa, a study on adolescents found that the prevalence of PTSD was $26.9 \%$, depression $17.6 \%$, and GAD $12.0 \%$. Proportion of adolescents with any diagnosis was $37.9 \%$. Comorbidity was found in $39.0 \%$ of adolescents with a psychiatric diagnosis. Adolescents from middle SES were more affected. Prolonged periods of helplessness and lack of adequate post-disaster psychological support were perceived as probable influencing factors other than the severity of the disaster (Kar, \& Bastia, 2006). Another study on children following the super-cyclone, found that PTSD presentations were similar to that in other cultures. It was felt that, though highly prevalent, PTSD might be missed without clinical 


\section{Natural Disaster and Its Devastation}

screening. PTSD was present in 30.6\%, and an additional 13.6\% had sub-syndromal PTSD. Parents or teachers reported mental health concerns in $7.2 \%$ subjects, who were only a minor proportion (12.8\%) of subjects with any syndromal diagnosis. Significantly more (43.7\%) children in high-exposure areas had PTSD than those (11.2\%) in low-exposure areas. Depression was significantly associated with PTSD. High exposure, lower educational level and middle SES significantly predicted PTSD. Extreme fear and perceived threat to life during disaster, death in family, damage to home, stay in shelters were not significantly associated with PTSD in children (Kar, Mohapatra, Nayak, Pattnaik, Swain \& Kar, 2007). The prevalence rates for psychiatric disorders (27.2\%) and psychological symptoms (79.7\%) around six to nine months following the tsunami in coastal Tamil Nadu have been considerable. The commonest psychiatric disorder was depression, followed by alcohol use disorders in males and anxiety disorders in females. The rate of PTSD, 12.5/1000, was found to be lower than expected (Nambi, Desai, \& Shah, 2007).

In a study of tsunami-affected males in Kanyakumari, 43\% had clinically significant psychological distress, and 31\% had very high levels of psychological distress. Individuals with higher frequency of personal prayer, better quality of marital life, job satisfaction were relatively protected; whereas substance abuse and severe disaster experience such as losing a family member were risk factors for severe psychological distress (George, Sunny, \& John, 2007).

Initial assessment in the Andaman and Nicobar Islands during the early phase of the 2004 tsunami disaster revealed 5-8\% of the population was suffering from significant mental health problems. The authors expected that the psychiatric morbidity would be around $25-30 \%$ in the disillusionment phase. High resilience was seen in the joint family system of the tribal Nicobarese (Math, Girimaji, Benegal, Uday Kumar, Hamza, \& Nagaraja, 2006). Psychiatric morbidity in these islands during the first three months following the earthquake and tsunami was significantly more (5.2\%) in the displaced population than (2.8\%) the non-displaced. The overall psychiatric morbidity was 3.7\%. The disorders included panic disorder, unspecified anxiety disorder, and somatic complaints. The existence of an adjustment disorder was significantly higher in the non-displaced survivors. Depression and PTSD were distributed equally in both groups (Math, John, Girimaji, Benegal, Sunny \& Krishnakanth, 2008).

The most common psychiatric morbidities in children and adolescents as primary (exposed directly to tsunami and earthquake) and secondary (those with close family and personal ties with primary survivors) survivors in the Andaman and Nicobar were adjustment disorder (13.5\%), depression (13.5\%), panic disorder (10.8\%), PTSD (10.8\%), schizophrenia (2.7\%), and other disorders (43.2\%). Sub-clinical syndrome was present in the majority of the primary and secondary survivors. A majority of survivors required community-based group interventions (Math, Tandon, Girimaji, Benegal, Kumar \& Hamza, 2008). Fire disasters are common in India. A study in a Delhi slum following a fire disaster reported that the prevalence of psychiatric disorders was significantly higher (7.8\%) compared to that $(2.2 \%)$ in the control group; prevalence of psychological ill health was also higher (23.2\% vs. 5.0\% respectively). The 
common psychiatric disorders were depression, substance use disorders, GAD and somatoform disorder. Age and participation in relief work were found to be strong predictors and physical injuries were found to be a weak predictor of mental health morbidity (Desai, Gupta, \& Srivastava, 2004). Following a fire disaster in Bangalore in 1981, 35.8\% of the bereaved relatives had psychiatric symptoms requiring treatment (Desai, Gupta, \& Srivastava, 2004, \& Narayanan, Sathyabati, Nardev, \& Thakar, 1987). In another study, following Mandi Dabwali fire disaster 56\% of children had PTSD after two months (Sharma, Rao \& Srinivas, 1998).

\section{PSYCHOLOGICAL INTERVENTION}

More recently, there has been a revived interest in 'psychological first aid' as first described by Raphael (1986) (Raphael, 1986)

* For use in the civilian domain.

\section{The principal components of psychological first aid}

- Comfort and consolation

- Protection from further threat and distress

- Immediate physical care

- Goal-oriented and purposeful behaviour

- Helping reunion with loved ones

- Sharing the experience (but not forced)

- Linking survivors with sources of support

- Facilitating a sense of being in control

- Identifying those who need further help (triage)

* Psychologists also learned that to be most effective, they need to team with other service providers ranging from school personnel to first responders, public health and health personnel, volunteers, and spiritual providers. By training these individuals in principles of disaster relief, including the basics of CBT, psychologists provide a valuable role by expanding their reach beyond the victims who they can help.

* 8 steps recommended by disaster behavioral health professionals:

1. Be prepared, pragmatic, and flexible. Know ahead of time what's going to be needed throughout the duration of the recovery period.

2. Promote a sense of safety. Give survivors a sense of calm, hope, connectedness, and boost their feelings of being able to cope with the crisis. 
3. Do no harm. Know what strategies work and which do not. Take into account the resources available in the community. Be sensitive to cultural differences among victims and respect their rights. Be open to feedback on your effectiveness.

4. Build on community resources. Work with families, communities, schools, and friends and maximize the participation of everyone who's been affected.

5. Integrate with existing larger systems. Design programming that will reach as many people as possible and reduce the stigma of seeking help. Avoid building stand-alone programs that replicate other available services.

6. Provide "stepped care." Adjust the type of helping to the phase of the disaster. Early intervention calls for different strategies than later interventions.

7. Provide support that reaches out to the community. Help the community understand what you're trying to do, and frame your efforts in terms of the community's cultural, religious, memorial, and spiritual needs.

8. Provide a spectrum of services. Intervention efforts should include assessment, Psychological First Aid, outreach, training, treatment for individuals showing signs of continued distress, and promotion of resilience (Susan, 2011).

\section{CONCLUSION}

Natural disasters (like Nepals earthquake) are an act of God and unstoppable, having the necessary precautionary measures in place to ensure that people are well prepared for the same goes a long way to ease the burden associated with such burdens making it less difficult to handle. If more people seek to get educated on such aspects, it becomes easier to handle any eventualities.. It is precisely due to these facts that the importance of preparedness cannot be overstressed. To cap it all, the world should unite in handling such occurrences to ease the burden placed on individual countries and especially those termed as third world countries.

\section{REFERENCES}

"25 dead, 383 injured in Tibet following Nepal earthquake". Xinhua. 2015.

"4 killed, 18 Bangladesh districts affected in earthquake, says govt". Bdnews24.com. 2015.

"7.3 Magnitude Earthquake hits North India including Bihar". news.biharprabha.com. 2015.

"90 Britons missing as Nepal earthquake death toll rises". The Himalayan Times via RT. 2015.

"Andhra Pradesh earthquake update: Aftershocks of Nepal Earthquake felt in Visakhapatnam, Godavari and Srikakulam districts". 2015.

"Earthquake Again in Nepal 12 May 2015". The Natural Disasters.

"Experts had warned for decades that Nepal was vulnerable to a killer quake". Washington Post. 2015. 
"Fresh Tremors in North India, Including Delhi, a Day After Nepal Earthquake". NDTV. 2015.

"Gorkha Earthquake is followed by 262 numbers of Earthquakes". Nepal Seismological Centre. 2015.

"In pics: 5,500 killed, more than 1/4th of Nepal's population affected after horrific earthquake".

"Incident Report of Earthquake 2015". Nepal Disaster Risk Reduction Portal. drrportal.gov.np. 2015.

"M6.7 - 17km S of Kodari, Nepal". usgs.gov.

"M7.8 - 34 km ESE of Lamjung, Nepal". United States Geological Survey. 2015.

"Massive 7.9 Earthquake jolts Bihar, North India and Nepal". news.biharprabha.com. 2015.

"National Emergency Operation Centre". National Emergency Operation Centre (Nepal Govt.) on Twitter (in Nepali). 2015.

"Nepal earthquake, magnitude 7.3, strikes near Everest". BBC News. 2015.

"Nepal earthquake: Eerie reminder of 1934 tragedy".

"Nepal Economy Devastated Following Earthquake". PrimePair. 2015.

"Nepal’s Slowing Economy Set for Freefall Without Global Help". Bloomberg Business. 2015.

"Quake toll in India now 78". Zee News. 2015.

"The Latest on Nepal Quake: Aid arriving as deaths top 4,000". The New Indian Express. 2015.

"Timeline: Nepal 2015 to 1934, the worst quake disasters in the last 80 years". 2015.

"Tremors felt in Delhi, Metro services briefly disrupted".

"Up to 250 missing after avalanche hits Nepal trekking route". "Mail Online". 2015.

"Earth Quake-hit Nepal at high risk of landslides in coming weeks". Free Press Journal.

"Everest's avalanche, through the climbers' eyes". Washington Post. 2015.

"katmandu-nepal-fear-loss-and-devastation”, nytimes.com, 2015.

"LIVE: Death toll rises to 2200 in Nepal earthquake, India resumes rescue ops". The Indian Express. 2015.

"M7.3 - 18km SE of Kodari, Nepal". United States Geological Survey. 2015.

"National Emergency Operation Centre". National Emergency Operation Centre (Nepal Govt.) on Twitter (in Nepali). 2015.

“The Latest on Nepal: In Ravaged Hamlets, Lives Were Spared”, U.S. News and World Reports, 2015.

"Trapped at 20,000 feet: Hundreds of Everest climbers await choppers as supplies run low". Fox News. The Associated Press. 2015.

"What 1934 Told Nepal to Expect About the Next Big Quake".

2011-2015 Disasterium.com.

Chidanand, R. ( 2015). "Is this the 'Big Himalayan Quake' we feared?". The Times of India.

China Earthquake Networks Center. 2015.

China News. 2015.

Cohen, R. E. (2002). Mental health services for victims of disasters. World Psychiatry. Colin, S. (2015). "Nepal earthquake: 'A tragedy waiting to happen' - CNN.com". CNN. 
Desai, N.G., Gupta, D.K., \& Srivastava, R.K. (2004). Prevalence, pattern and predictors of mental health morbidity following an intermediate disaster in an urban slum in Delhi: A modified cohort study. Indian J Psychiatry.

Desai, N.G., Gupta, D.K., \& Srivastava, R.K. (2004). Prevalence, pattern and predictors of mental health morbidity following an intermediate disaster in an urban slum in Delhi: A modified cohort study. Indian J Psychiatry.

Desai, N.G., Gupta, D.K., \& Srivastava, R.K. (2004). Prevalence, pattern and predictors of mental health morbidity following an intermediate disaster in an urban slum in Delhi: A modified cohort study. Indian J Psychiatry.) (Narayanan, H.S., Sathyabati, K., Nardev, G. \& Thakar S. (1987). Grief reaction among bereaved relatives following a fire disaster in a circus. NIMHANS J.

Fairclough, P. ( 2011). 15.45 GMT Last modified on Tuesday 20 May 201408.41 BST.

George, C., Sunny, G., \& John, J. (2007). Disaster experience, substance abuse, social factors and severe psychological distress in male survivors of the 2004 tsunami in South India. Indian J Psychiatry.

Hjelmgaard, K. (2015). "Nepal hit by major aftershock as search for quake survivors intensifies". USA Today.

J:Idisaster manegementlTypes of Disaster - Natural and Man-Made - Restore Your Economy.html

Jason, B. \& Ishwar, R. (2015). in Kathmandu. "Nepal earthquake death toll exceeds 6,000 with thousands unaccounted for | World news". The Guardian.

Juan, J., George, C., Mario, M., Norman, S., \& Ahmed, O. (2002). AN INTEGRATED APPROACH TO DISASTER MANAGEMENT - WHO PERSPECTIVE OF PREVENTIVE PSYCHIATRY,( Disasters and Mental Health ; Appendix - Statement by the World Psychiatric Association on Mental Health Implications of Disasters (approved by General Assembly).

Kaini, S. (2015). "Great Earthquake wipes out Barpak". The Kathmandu Post.

Kar, G.C. (2000). Disaster and mental health. Indian J Psychiatry.

Kar, N. \& Bastia, B.K. (2006). Post-traumatic stress disorder, depression and generalised anxiety disorder in adolescents after a natural disaster: A study of comorbidity. Clin Pract Epidemiol Mental Health.

Kar, N., Jagadisha, T., Sharma, P.S., Murali, N. \& Mehrotra, S. (2004). Mental health consequences of the trauma of supercyclone 1999 in Orissa. Indian J Psychiatry.

Kar, N., Mohapatra, P.K., Nayak, K.C., Pattnaik, P., Swain, S.P. \& Kar, H.C. (2007). Posttraumatic stress disorder in children and adolescents one year after a super-cyclone in Orissa, India: Exploring cross-cultural validity and vulnerability factors. BMC Psychiatry.

Khandelwal, S.K. (2006). The joy of mental health: Some popular writings of Dr. NN Wig Book Review. Indian J Psychiatry.

Koshi Highway obstructed". ekantipur.com. 2015. 
Los Angeles Times (2015). "Google employee killed in avalanche was 'adventure activist,' friends say". latimes.com.

Manesh, S. (2015). "Death toll from this week's Nepal earthquake rises above 125". CNN.

Manesh, S., Jethro, M., \& Laura, S.S. (2015). "Nepal's latest earthquake: Death toll climbs above 100". CNN.

Math, S.B., Girimaji, S.C., Benegal, V., Uday Kumar, G.S., Hamza, A. \& Nagaraja, D. (2006). Tsunami: Psychosocial aspects of Andaman and Nicobar islands. Assessments and intervention in the early phase. Int Rev Psychiatry.

Math, S.B., John, J.P., Girimaji, S.C, Benegal, V., Sunny, B. \& Krishnakanth, K. (2008). Comparative study of psychiatric morbidity among the displaced and non-displaced populations in the Andaman and Nicobar Islands following the tsunami. Prehosp Disaster Med.

Math, S.B., Tandon, S., Girimaji, S.C., Benegal, V., Kumar, U. \& Hamza, A. (2008). Psychological impact of the tsunami on children and adolescents from the andaman and nicobar islands: Prim Care Companion J Clin Psychiatry.

McCarthy, J. ( 2015). "He Carried His Mom On His Back For 5 Hours En Route To Medical Care". Montana Public Radio.

Mohandas, E. (2009). Roadmap to Indian Psychiatry. Indian J Psychiatry.

Nambi, S., Desai, N.G. \& Shah S. (2007). Mental health morbidity and service needs in tsunami affected population in coastal Tamil Nadu. Indian J Psychiatry.

Rao, T.S.S. (2004). Managing impact of natural disasters: some mental health issues. Indian J Psychiatry.

Raphael, B. (1986). When Disaster Strikes. How Individuals and Communities Cope with Catastrophe. New York: Basic Books.

Sharan. P., Chaudhary, G., Kavathekar, S.A., \& Saxena, S. (1996). Preliminary report of psychiatric disorders in survivors of a severe earthquake. Am J Psychiatry.

Sharma, A., Rao, S. \& Srinivas, S. (1998). Mandi Dabwali fire disaster. Psychological impact on school children after two months-preliminary findings. Indian J Psychiatry.

Shrestha, S. ( 2015). "Langtang is gone". Nepali Times.

Susan, K. W. (2011). How to Manage Traumatic Reactions to Disasters

Taylor, A. \& Frazer, A. (1982), The stress of post-disaster body handling and victim identification work. Journal of Human Stress. 